\title{
LAS ACTIVIDADES ECONÓMICAS EN LA MONTAÑA ORIENTAL LEONESA DURANTE LA EDAD MODERNA
}

\author{
Aitor GARCÍA GARCÍA
}

Recibido: $12 / 03 / 2012$

Aceptado: 04/11/2013

RESUMEN: El presente trabajo trata fundamentalmente sobre los aspectos económicos y en menor medida sociales en el marco de la Montaña central y oriental leonesa durante la Edad Moderna. Se analiza la incidencia de actividades económicas como la agricultura, la ganadería, el pastoreo, la artesanía, la arriería y el comercio en el siglo XVIII, así como también se analizan ciertos aspectos demográficos.

PALABRAS CLAVE: Edad Moderna, Montaña leonesa, arriero, comercio

ABSTRACT: The present paper is based in social and economic aspects during the modern age from Leon's East Mountain. We analyce the economic impact of activities like agriculture as well as livestock farming, shepherding, craftsmanship, the muleteers and commerce during $18^{\text {th }}$ century, as well as demographics aspects.

KEYWORDS: Modern Age, Leon's Mountain, muleteer, commerce.

\section{INTRODUCCIÓN}

\subsection{EI marco geográfico: la Montaña leonesa}

La montaña oriental leonesa, que se localiza en el norte y noreste de la provincia ${ }^{1}$, ocupa algo más $2000 \mathrm{~km}^{2}$ de superficie y presenta una altitud media de unos 1500 metros. Limita al norte con el Principado de Asturias, al noreste con la Comunidad Autónoma de Cantabria y al este con la provincia de Palencia. En este territorio los inviernos son largos y fríos, con copiosas nevadas, y los veranos cortos y no muy cálidos. Debido a la influencia que ejerce sobre la región el clima oceánico, son frecuentes las lluvias. La fauna, que en otro tiempo fue parte del alimento de los montañeses y de las preocupaciones de sus ganaderos, en la

\footnotetext{
${ }^{1}$ Véase la obra de Modesto BRAVO: «La Montaña» en Tierra leonesa: ensayo geográfico sobre la provincia de León. León 1929, pp.68-74
} 
actualidad sigue siendo rica y variada, a pesar del descenso demográfico que están padeciendo ciertas especies. Por lo que respecta a la flora, la Montaña oriental leonesa ha destacado por sus importantes bosques de robles y hayedos, que jugaron un importante papel en al economía de sus moradores, sin olvidar otras especies como el acebo, el fresno, el abedul o el pino.

Por otra parte, la organización territorial y administrativa de la mencionada región, estaba estructurada en torno a los Concejos. El Concejo Mayor, caso, por ejemplo, de Valdeburón, Valdeón o Tierra de la Reina, que aglutinaba una serie de localidades o entidades menores, y estaban gobernados por un representante de cada una de ellas. Por su parte, en cada una de esas comunidades de aldea operaba el Concejo Menor. En éste, y al frente de una autoridad local, el regidor, se reunían todos los vecinos cabezas de familia con el objetivo de tratar los temas o asuntos concernientes a la comunidad ${ }^{2}$. Esas reuniones, de obligada asistencia, eran convocadas por los regidores concejiles. Normalmente, las ordinarias se celebraban los domingos a la salida de misa. El concejo abierto o general de vecinos regulaba, por medio de las ordenanzas concejiles, la vida de las villas y pueblos leoneses, a pesar de que muchos de ellos estaban bajo la jurisdicción señorial o de otros poderes dominantes. El concejo acordaba, decidía, controlaba, abría pesquisas, distribuía los recursos y, en fin, servía de marco para desarrollar actividades colectivas y lúdicas, como la socialización del consumo del vino a través de la copa de concejo. Democracia directa y autogestionaria, comunitarismo y colectivismo vecinal son algunos de los calificativos que presidieron un sistema en torno al que se reprodujeron durante siglos la mayor parte de las comunidades leonesas ${ }^{3}$.

\subsection{Los recursos demográficos}

A través del Censo de Floridablanca, elaborado en 1787, podemos conocer el volumen demográfico de la Montaña Oriental leonesa, así como la distribución por sexos.

Se puede constatar que hay más mujeres que hombres (11.693 por 11.257), siendo el 50,95 de la población mujeres, y el 49,05 restante hombres.

2 Para más información sobre el tema véase los trabajos de RUBIO PÉREZ, L., El sistema político concejil en la provincia de León durante la Edad Moderna. León, 1993. Universidad de LeónFundación Monteleón.

${ }^{3}$ Rubio PÉREZ, L., «Gobierno y poder local: regimientos y concejos», en La Historia de León. Edad Moderna (VV.AA.), León, pp.107-132. 


\begin{tabular}{lrrr}
\hline \multicolumn{1}{c}{ Concejo o pueblo } & Población & Varones & Mujeres \\
\hline Valdelugueros & 1.051 & 518 & 533 \\
Valdeburón & 2.167 & 1.056 & 1.111 \\
Valdeón & 905 & 434 & 471 \\
Modino & 610 & 311 & 299 \\
Redipollos & 1.063 & 533 & 530 \\
Sajambre & 672 & 343 & 329 \\
Encartación de Curueño & 1.115 & 534 & 581 \\
Peñamián & 1.465 & 709 & 756 \\
Condado de Colle & 581 & 280 & 301 \\
Valderrueda & 1.982 & 982 & 1.000 \\
Ribesla & 456 & 228 & 228 \\
Valle de Curueño & 1.525 & 738 & 787 \\
Valdoré & 486 & 248 & 238 \\
Valdellorma & 829 & 419 & 410 \\
Ventanillo & 212 & 108 & 104 \\
Urbayos & 334 & 169 & 165 \\
Tierra de la Reina & 1.859 & 919 & 940 \\
Boñar & 1.309 & 632 & 677 \\
La Vega de Boñar & 914 & 440 & 474 \\
Aleón & 916 & 450 & 466 \\
Las Arrimadas & 331 & 155 & 176 \\
Acebedo & 314 & 162 & 152 \\
Cofiñal & 298 & 146 & 152 \\
La Losilla y San Adrián & 91 & 43 & 48 \\
Liegos & 180 & 79 & 101 \\
Puebla de Lillo & 509 & 244 & 265 \\
Riaño & 512 & 251 & 261 \\
Tejerina & 181 & 83 & 98 \\
La Braña & 83 & 43 & 40 \\
\hline Total & 22.950 & 11.257 & 11.693 \\
\hline
\end{tabular}

La siguiente tabla trata sobre el envejecimiento de la población. Después de haber realizado los cálculos pertinentes podemos afirmar que la población de la Montaña oriental leonesa a finales del siglo XVIII tendía al envejecimiento, ya que tiene un indicador 43,52, sobrepasando el indicador 40 que es el límite entre una población joven y una vieja.

\begin{tabular}{ccc}
\hline Población mayor de 50 años & Población entre 0 y 16 años & Indicador \\
\hline 3.563 & 8.187 & 43,52 \\
\hline
\end{tabular}


Breve aproximación a la estructura de la población de la montaña oriental leonesa en 1787. Censo de Floridablanca

\begin{tabular}{lrrrrrrrrr}
\hline \multirow{2}{*}{ Grupos edades } & \multicolumn{3}{c}{ Varones } & \multicolumn{3}{c}{ Mujeres } & \multicolumn{3}{c}{ Total } \\
\cline { 2 - 9 } & $S$ & $C$ & $V$ & $S$ & $C$ & $V$ & Var. & Muj.s & Total \\
\hline Menos de 7 & 239 & 0 & 0 & 224 & 0 & 0 & 239 & 224 & 463 \\
De 7 a 16 & 273 & 0 & 0 & 255 & 0 & 0 & 273 & 255 & 528 \\
De 16 a 25 & 193 & 38 & 1 & 205 & 38 & 1 & 232 & 244 & 476 \\
De 25 a 40 & 63 & 244 & 7 & 83 & 262 & 8 & 314 & 353 & 667 \\
De 40 a 50 & 16 & 136 & 7 & 8 & 137 & 9 & 159 & 154 & 313 \\
Más de 50 & 7 & 147 & 59 & 27 & 128 & 97 & 213 & 252 & 465 \\
\hline & 791 & 565 & 74 & 802 & 565 & 115 & 1430 & 1482 & 2912 \\
\hline
\end{tabular}

S, solteros/as; C, casados/as; V, viudos/as; Var., varones; Muj., mujeres

\section{EL MODELO ECONÓMICO}

Como en todas las sociedades pre-industriales la principal base económica fue el trabajo de la tierra, y en este sentido la sociedad leonesa de la Edad Moderna no fue una excepción. Sin embargo, la Montaña leonesa es una zona poco apta para el desarrollo agrícola, con lo que aquí el mayor protagonismo lo ostenta la ganadería. En la zona meridional la ganadería actúa como complemento de la agricultura, y en cambio en el septentrión los papeles se permutan. Por otra parte, las actividades que podemos encuadrar en los sectores secundario y terciario tienen menor importancia. Dentro de los oficios los más destacados son el de sastre, tejedor, herrero y carpintero. Por parte de las actividades terciarias hay presencia de escribanos, secretarios, sangradores, taberneros y comerciantes, o mejor dicho tratantes, quienes comercian fundamentalmente con leña y sobre todo con vino.

\subsection{Las actividades básicas o principales}

\subsubsection{La agricultura: principales aspectos y cultivos}

Los condicionantes morfológicos, entre los que destacan la altitud, el clima, el tipo de suelo, la orografía, etc., determina en gran medida el tipo de economía propio de una zona o región ${ }^{4}$. Uno de los aspectos más característicos de la Montaña leonesa fue la presencia de espacios no cultivados de propiedad comunal, bien usados para pasto o arriendo. Esto significaba para los campesinos la gratuidad en el sustento de la cabaña ganadera, la cual formaba parte del círculo productivo, siendo fundamental para las capas sociales más bajas. Además de

\footnotetext{
${ }^{4}$ PÉRez Álvarez, M.J.: «La organización del terrazgo: estructura y dinámica», en La Montaña noroccidental leonesa en la Edad Moderna, pp. 113-148, 1996.
} 
utilizar el terreno comunal para pastar el ganado, también se aprovechaban las partes más bajas del monte, que podían ser roturadas y de este modo ampliar el área de labranza, siempre y cuando lo autorizara el concejo, el administrador de la comunidad. De las superficies no cultivadas también forman parte los puertos de montaña, cuestión que se abordará en el apartado dedicado al pastoreo.

En líneas generales se puede afirmar que los campesinos montañeses trabajaban una hacienda de dimensiones reducidas y completaban su actividad con la posibilidad de utilizar los pastos propiedad del «común», siendo un sistema de agricultura pastoril. ${ }^{5}$ El sistema de cultivo más común era el de año y vez, aunque éste no se seguía para cultivos como el lino, el centeno, ni para las hortalizas en los huertos. Debido a las condiciones climáticas y edafológicas de una zona montañosa como ésta, es muy posible que hubiera espacios cultivados en los que el descanso de la tierra fuera mayor. Siguiendo como ejemplo el valle de Boñar, que puede servir de modelo para la Montaña central y oriental leonesa, el cultivo más importante fue el de los cereales, y dentro de éstos, el centeno, producido en mayor cantidad que los demás y con el que se hacía el pan, esencial en la dieta de los montañeses. En el caso de la villa de Boñar la importancia del trigo aumenta a partir del último cuarto del siglo XVIII, debido al alza de su precio. También se cultivaba la cebada. Además del cultivo de estos tres cereales también se cultivaba un trigo de primavera llamado corricasa o tremesino, llamado de este modo por su duración en el ciclo productivo, pero el aumento de la producción de trigo y la entrada de la patata arrinconan a este cereal, que terminó por desaparecer en la década de 1830 . Se empleaba en la alimentación humana y no se mezclaba con otro cereal para hacer pan. Además se cultivaban las legumbres y el lino, pero tenían menor importancia que los cereales. En cambio otros cultivos como las patatas o el maíz no se sembraron hasta principios del siglo XIX.

\subsubsection{La ganadería}

La ganadería fue una actividad económica fundamental para la Montaña leonesa durante la Edad Moderna, dado que en ciertas zonas donde la labor agrícola no tiene tanto peso, es la ganadería el motor económico. La ganadería fue uno de los elementos determinantes en las economías de Antiguo Régimen, independientemente de que su papel fuera el de protagonista o actuara como complemento $^{6}$. Este bien móvil, preciadísimo, nunca fue dejado de lado, poseer

5 TASCÓN FERNÁNDEZ, L.J.: «Aumento de la producción de trigo en las montañas de León a finales del Antiguo Régimen». Tierras de León, $\mathrm{n}^{\circ}$ 71, 1988.

${ }^{6}$ SLICHER VAN BATH, B.H. (1978), p. 415. Este autor nos da las cuatro razones fundamentales por las que el ganado es uno de los elementos económicos de interés para el campesino. 
ganado era un seguro, «casi de vida», en coyunturas agrarias recesivas ${ }^{7}$. La importancia del ganado reside en la polivalencia que puede alcanzar en la explotación en la que participa. Los animales son productores de estiércol, que es fertilizante de los campos e indispensable para la regeneración del suelo; de lácteos y carne, que se emplearán directamente en la alimentación humana o en pequeñas industrias transformadoras; de los animales se pueden obtener materias primas para las industrias del cuero; y, a su vez, y de extrema trascendencia durante siglos, vacuno, équidos y asnal aportan fuerza motriz, ya sea para el tiro o como medio de transporte, etc... Todo ello, sin dejar de lado el papel que cumplieron como bienes objeto de especulación.

Por lo general el régimen de explotación del ganado era la aparcería, cediendo los animales las Cofradías del pueblo o las de las aldeas cercanas. Los animales se utilizaban en las labores del campo, como bestias de carga para acarrear todo tipo de objetos, y solo en contadas ocasiones comían su carne, sobre todo si se trataba de ganado vacuno, y éste se encontraba en mal estado, es decir, si sufría algún accidente irreversible ${ }^{8}$.

A mediados del siglo XVIII, la provincia de León representaba el 4,2\% del territorio de la antigua Corona de Castilla, en ella se acomodaba el 3,7\% de la población de la misma y era poseedora del $5 \%$ de las reses ${ }^{9}$ que en aquella época había en dicha Corona. Comparadas las magnitudes que aportaba León respecto a la totalidad del territorio español, esta provincia ocupaba un 3\% de la superficie, en ella vivían el 2,6\% de los habitantes y el 4,2\% de los animales domésticos.

A pesar de la importancia de la actividad en todo la Montaña leonesa, hay que diferenciar una zona que hemos denominado «alta», cuyo límite por el Sur se localiza en torno a la localidad de Reyero y otra «baja», que se extiende desde la mencionada localidad hasta la zona de El Curueño. El ganado lanar fue el más destacado, hasta el punto de que la mitad de las cabezas de ganado eran carneros, ovejas o corderos. En importancia numérica le siguen las cabras y machos cabríos, encontrándose a más distancia los bueyes, vacas y terneros y aún más los cerdos.

${ }^{7}$ Vid. Domínguez Martín, R. y De La Puente Fernandez, L. (1995), p. 73. Cuando subía el precio del grano los ganaderos se deshacían «desesperadamente» de sus reses para paliar la crisis frumentaria.

${ }^{8}$ TASCÓn FERNÁNDEZ, L.J.: «Aumento de la producción de trigo en las montañas de León a finales del Antiguo Régimen». Tierras de León, ${ }^{\circ}$ 71, 1988.

${ }^{9}$ Aunque se trata de cifras bastante halagüeñas, en ningún momento pueden comparase con las que el ganado gallego representó en la Corona de Castilla, ni a nivel de territorio español. Véase EIRAS RoEl, A. (1983), p. 436. 
En la zona que hemos denominado «alta» tienen una mayor importancia los équidos, lo que es debido a que al ser una zona de escaso desarrollo agrícola, la arriería constituye una actividad económica fundamental que suplanta al trabajo de la tierra.

La zona «alta» está compuesta por los siguientes concejos y entidades locales: Valdelugueros, Peñamían, Redipollos, Tierra de la Reina, Valdeburón, Sajambre, Posada de Valdeón, Acebedo, Cofinal, La Braña, Tejerina, Riaño, Liegos y Puebla de Lillo.

\begin{tabular}{|c|c|c|}
\hline Tipo de ganado & Cabezas de ganado & $\%$ \\
\hline Bueyes, vacas y terneros & 12.690 & 17,9 \\
\hline Caballos, yeguas y potros & 3.243 & 4,6 \\
\hline Mulas y machos & 5 & 0,007 \\
\hline Pollinos y jumentas & 0 & 0 \\
\hline Carneros, ovejas y corderos & 32.240 & 45,4 \\
\hline Machos cabríos, cabras y cabritos & 16.996 & 23,9 \\
\hline Cerdos & 4.131 & 5,8 \\
\hline Colmenas & 1.689 & 2,4 \\
\hline Palomares & 7 & 0,01 \\
\hline Total & 71.001 & 100 \\
\hline
\end{tabular}

Mientras que la denominada zona «baja», más ligada a la agricultura, la componen los concejos de: Boñar, La Vega de Boñar, Colle, Las Arrimadas, Encartación de Curueño, Ribesla, Valderrueda, Valdoré, Modino, Valdetuéjar, Guzpeña, Valdellorma, Aleón, Urbayos y Ventanillo.

\begin{tabular}{|c|c|c|}
\hline Tipo de ganado & Cabezas de ganado & $\%$ \\
\hline Bueyes, vacas y terneros & 12.223 & 11,9 \\
\hline Caballos, yeguas y potros & 2.603 & 2,5 \\
\hline Mulas y machos & 127 & 0,1 \\
\hline Pollinos y jumentas & 169 & 0,2 \\
\hline Carneros, ovejas y corderos & 54.504 & 53,2 \\
\hline Machos cabríos, cabras y cabritos & 23.453 & 22,9 \\
\hline Cerdos & 6.267 & 6,1 \\
\hline Colmenas & 3.038 & 3 \\
\hline Palomares & 2 & 0,001 \\
\hline Total & 102.382 & 100 \\
\hline
\end{tabular}

\subsection{Las actividades complementarias}

Tanto el pastoreo como las actividades artesanales fueron en la Montaña 
leonesa un complemento de la actividad principal, bien ésta haya sido la agricultura o la ganadería. Aunque parece que actividades como la artesanía, el comercio o incluso el pastoreo tuvieron poco peso, fueron actividades importantes, pero realmente no se conoce el alcance económico de las mismas, con lo que intentaremos acercarnos a su incidencia en el marco de la Montaña leonesa. Si bien, será fundamentalmente la Montaña oriental la zona en la que centramos el trabajo, no podemos olvidarnos de la Montaña central.

\subsubsection{Los pastores}

El pastoreo fue una actividad importante en la economía de la Montaña leonesa, teniendo como protagonista a la oveja. El desarrollo de la trashumancia fue clave para la economía de la Montaña leonesa, ya que permitió aliviar las economías familiares en dos sentidos. En primer lugar el arrendamiento de los puertos de montaña tuvo una gran importancia económica para aquellos pueblos o lugares que lo llevaron a cabo. Los protagonistas son los concejos, quienes anualmente arriendan los puertos a las cabañas merinas trashumantes procedentes del Sur que se dirigen a León para pasar el verano y de esta manera obtenían unos ingresos que iban a parar directamente a la comunidad. En segundo lugar, la contratación de pastores que se dirigían al Sur para cuidar los rebaños suponía una mejora de la situación económica familiar, ya que suponía tener que alimentar varias «bocas menos».

Como ejemplo tenemos la contratación de pastores del alto Esla en Ciudad Real, cuya situación nos la describe las Respuestas Generales del Catastro de Ensenada del año 1751. Podemos afirmar que hubo una gran contratación de pastores leoneses, algunos de los cuales optaron por asentarse de forma definitiva en las tierras sureñas. En ocasiones, además del nombre del pastor y su lugar de procedencia, se nos informa de su edad y de su estado civil. La mayoría procedía de la Tierra de la Reina, aunque lugares como Riaño, Valderrueda, Acebedo, La Uña, Lois, Lario o Maraña también aportaron una gran cantidad de pastores.

\subsubsection{Los artesanos}

Las actividades artesanales fueron siempre secundarias y complementarias de la agricultura y la ganadería en la Montaña leonesa. Las principales ocupaciones son muy básicas: carpinteros, sastres, herreros, cerrajeros, algún tallista, tejedores, algún fabricante de $\operatorname{costanas}^{10}$, canteros. No ocupan a una gran parte de la

\footnotetext{
${ }^{10}$ Cada uno de los zarzos o tablas que se ponen en los costados del carro para que no se caiga lo que va en él.
} 
población, sino que por lo general hay pocos vecinos que se dediquen a estos trabajos. Muchas actividades no tenían prácticamente demanda, ya que muchos vecinos que se dedican a la artesanía realizan estos trabajos para satisfacer sus necesidades, tendiendo a la autarquía. Por otra parte, muchos artesanos compatibilizaban el trabajo artesanal con el trabajo de la tierra, pero en realidad no sabemos qué actividad era complementaria y cual principal. Los artesanos que más habitualmente nos encontramos en la mayoría de los concejos son carpinteros, sastres y herreros.

\begin{tabular}{lrr}
\hline \multicolumn{1}{c}{ Actividad artesanal } & Cantidad & $\%$ \\
\hline Herrero & 45 & 6,9 \\
Carpintero & 24 & 3,7 \\
Sastre & 61 & 9,4 \\
Tejedor & 64 & 9,9 \\
Tallista & 4 & 0,6 \\
Cerrajero & 9 & 1,4 \\
Cantero & 2 & 0,3 \\
Constructor de ruedas & 441 & 67,8 \\
\hline \multicolumn{1}{c}{ Total } & 650 & 100 \\
\hline
\end{tabular}

La gran mayoría de artesanos se dedicaban a la construcción de ruedas que encontraban salida a través del comercio con Castilla. Varios vecinos del concejo de Valdeburón se dedicaban a esta actividad y mediante el comercio conseguían unos ingresos extra, al igual que en Oseja de Sajambre. Los tejedores y los sastres les siguen en importancia.

\subsubsection{Los arrieros}

Para tratar la cuestión de los arrieros nos centraremos en la comarca de Los Argüellos. El concejo de Los Argüellos se localiza en la zona central de la Montaña leonesa y se divide en tres tercias: La Tercia del Camino, La Mediana y Valdelugueros.

La arriería fue una actividad a tener en cuenta en la provincia de León, ya que ésta se encuentra cerca de las costas y de los núcleos de población castellanos, con lo que el transporte de mercancías se convierte en una actividad bastante interesante desde el punto de vista económico ${ }^{11}$. Normalmente los arrieros poseían varias caballerías (la media de caballos por arriero se sitúa en 2,5), se dirigían a los

11 Cubillo de la Puente, R. (2006). Arrieros leoneses. La Montaña central: Gordón, Vegacervera, Los Arguellos. León: Nueva Comunicación. 
puertos de mar, núcleos urbanos importantes y sobre todo a la capital de la monarquía: Madrid. En sus rutas no podía faltar Asturias, región hacia donde partían a través de los puertos de Pajares, Piedrafita y Vegarada. Éste último era transitado por los arrieros de La Tercia de Valdelugueros, ruta que ya era utilizada en tiempos del emperador Carlos V. De vuelta con los productos asturianos, se dirigían a las ferias y mercados de Castilla la Vieja, utilizando los caminos marcados en las riberas de los ríos leoneses, sobre todo el Bernesga y el Torío, pero también el Curueño y el Porma, estos últimos transitados fundamentalmente por los de Valdelugueros. Por lo general no trabajaban por encargo, sino que se arriesgaban tanto en las compras como en las ventas. Los arrieros argollanos transportaban alimentos con destino principalmente a Asturias. Cuando viajaban de norte a sur comerciaban con productos alimenticios de origen animal.

En lo referente a las principales mercancías transportadas, éstas eran las siguientes. Fundamentalmente, los arrieros transportaban hacia el Sur productos alimenticios de origen animal: cecina de vacuno y caprino, derivados lácteos, otros derivados del ovino y caprino y pescado; para allí abastecerse de vino, producto que llevaban al Norte. Además de los productos citados, los arrieros también transportaron carne de cerdo y sus derivados, leche, manteca, queso, pescados, vino, aceites de linaza y oliva, legumbres y frutos secos, lino, cereales, pimentón, azúcar y patatas. Como se puede observar todos estos productos son de carácter alimenticio y de primera necesidad. Otros productos que podrían tener una demanda más reducida pero con los que también se comerció fueron el hielo y la nieve, fundamentalmente destinada a la ciudad de León; es posible que también se transportara y comerciara con velas de sebo; y otro producto que destacamos es el palo de Campeche, árbol originario de América Central usado como colorante rojizo para tejido y que también contaba con propiedades médicas.

Número de arrieros y caballerías del concejo de Valdelugueros (CUBILlo DE LA PUENTE, 2006)

\begin{tabular}{lrrrrr}
\hline \multicolumn{1}{c}{ Pueblo o localidad } & $N^{o}$ vecinos & $N^{o}$ arrieros & \% arrieros & $N^{o}$ caballer. & \% caballer. \\
\hline Arintero & 13 & 7 & 53,8 & 15 & 4,2 \\
Cerulleda-Redipuertas & 52 & 39 & 75 & 104 & 28,9 \\
Llamazares & 18 & 8 & 44,4 & 11 & 3,1 \\
Lugueros & 26 & 24 & 92,3 & 52 & 14,4 \\
Redilluera & 22 & 12 & 54,5 & 34 & 9,4 \\
Tolibia de Abajo & 21 & 15 & 71,4 & 38 & 10,5 \\
Tolibia de Arriba & 23 & 22 & 95,6 & 78 & 21,7 \\
Villaverde de la Cuerna & 23 & 15 & 65,2 & 28 & 7,8 \\
\hline \multicolumn{1}{c}{ Total } & 196 & 142 & 72,4 & 360 & 100 \\
\hline
\end{tabular}




\subsubsection{Otras actividades: comerciantes y profesiones del sector servicios}

Tanto el comercio como el sector servicios fueron actividades totalmente secundarias en la Montaña leonesa durante el Antiguo Régimen. Escribanos, escribanos reales, secretarios de número y ayuntamiento, notarios apostólicos, notarios públicos, abogados, taberneros, posaderos, tablajeros, sangradores, cirujanos, criados, son las principales profesiones u ocupaciones que aparecen en la documentación consultada para la Montaña leonesa en la Edad Moderna. Las profesiones citadas son las más comunes, estando presentes en casi todos los pueblos y concejos, pero con poca importancia cuantitativamente hablando. Menos habitual es encontrarse con personas dedicadas a la enseñanza, como lo demuestra el hecho de haber hallado solamente a un maestro de primeras letras en Lois, llamado Jerónimo García Canseco, otro maestro de primeras letras en Renedo de Valdetuéjar, y un preceptor de Gramática en Valderrueda.

Por otra parte los tratantes o comerciantes son menos comunes que los escribanos o los secretarios, pero aparecen en muchos concejos. Numéricamente no es un sector muy elevado, a lo que hay que añadir que además de sus actividades comerciales en la mayoría de los casos también son labradores, lo que no muestra que el comercio es una actividad secundaria y complementaria de la agricultura. En la documentación aparecen comerciantes de vino, de carros y ruedas, de almagre, de rocines, de leña. Los productos con los que se comercia son pocos y básicos. La actividad más importante es sin duda el comercio del vino, siendo el que a más individuos ocupa

El comercio del vino es una actividad que destaca en el concejo de Peñamián, en pueblos como Armada, Campillo, Valdehuesa, Vegamián, Viego hay varios vecinos que son tratantes de vino, y en otros lugares del entorno como en Ferreras, Orones, Rucayo y Utrero, varios vecinos se dirigen a Tierra de Campos para proveerse de vino, que luego venden en sus lugares de origen. También a Tierra de Campos para obtener vino se dirigen seis vecinos de La Mata de la Riba, dos de La Vega de Boñar y uno de Llamera.

Comercio de almagre ${ }^{12}$ : hallamos 40 comerciantes de este producto en el concejo de Sajambre. Estos comerciantes se dirigen con el almagre a las serranías de Segovia para allí venderlo y allí obtienen lino, que luego venden en sus lugares de origen. El almagre era usado en ocasiones para la escritura.

Comercio de madera y leña: en Pardesivil aparecen nueve comerciantes que se

${ }^{12}$ El almagre es un óxido rojo que se emplea en pintura. 
dirigen a vender la leña a la ciudad de León. Los tratantes de madera los encontramos en Llánaves de la Reina, siete en concreto, que además de esta actividad son labradores.

Tratantes de ganado: los encontramos en el concejo de la Guzpeña, y para ser más exactos en Llama de la Guzpeña y en Cerezal de la Guzpeña. En el concejo de Oseja hay varios vecinos que comercian con rocines.

En Siero de la Reina, jurisdicción de la Tierra de la Reina aparecen 25 vecinos que comercian con cambones ${ }^{13}$, siendo también labradores; y en otro pueblo de la misma jurisdicción, en Valverde de la Sierra hay 32 vecinos que comercian con carbón y también son labradores. En la villa de Boñar durante la celebración de una romería, acuden a la misma mercaderes de paño de León y comerciantes del Principado de Asturias. Estos últimos traen distintas mercancías para vender: tocino, frutas, manteca, habas. En la práctica mayoría de los concejos y pueblos los individuos dedicados al comercio son también labradores, con lo que podemos concluir que la práctica comercial es un complemento de la agricultura, que se erige en la actividad económica más importante de la región.

El siguiente cuadro muestra la incidencia de los sectores económicos en la Montaña oriental leonesa. Como se puede observar el sector primario domina el panorama económico de una forma aplastante, siendo la agricultura la actividad más destacada, aunque en ciertas zonas la ganadería tiene incluso un peso mayor, lo que es debido a la existencia de zonas poco aptas para el desarrollo agrícola. Por su parte, el sector secundario tiene una escasa relevancia al ocupar a un porcentaje mínimo de la población como principal ocupación, si bien es cierto que muchos artesanos también se dedicaban a la agricultura, siendo la artesanía una actividad complementaria de aquélla. Por último. el sector terciario se encuentra en una situación similar a la del secundario, si bien es cierto que cuenta con un porcentaje un poco mayor, y hay que señalar que la arriería es la principal ocupación, teniendo como principal área de actuación en la Montaña oriental leonesa el concejo de Valdelugueros. En el citado sector también destaca la ausencia de grandes comerciantes y financieros.

\begin{tabular}{cc}
\hline Sectores & $\%$ \\
\hline Primario & 94,7 \\
Secundario & 1,8 \\
Terciario & 3,5 \\
\hline
\end{tabular}

${ }^{13}$ Cambones: trozo de la rueda de la carreta. 